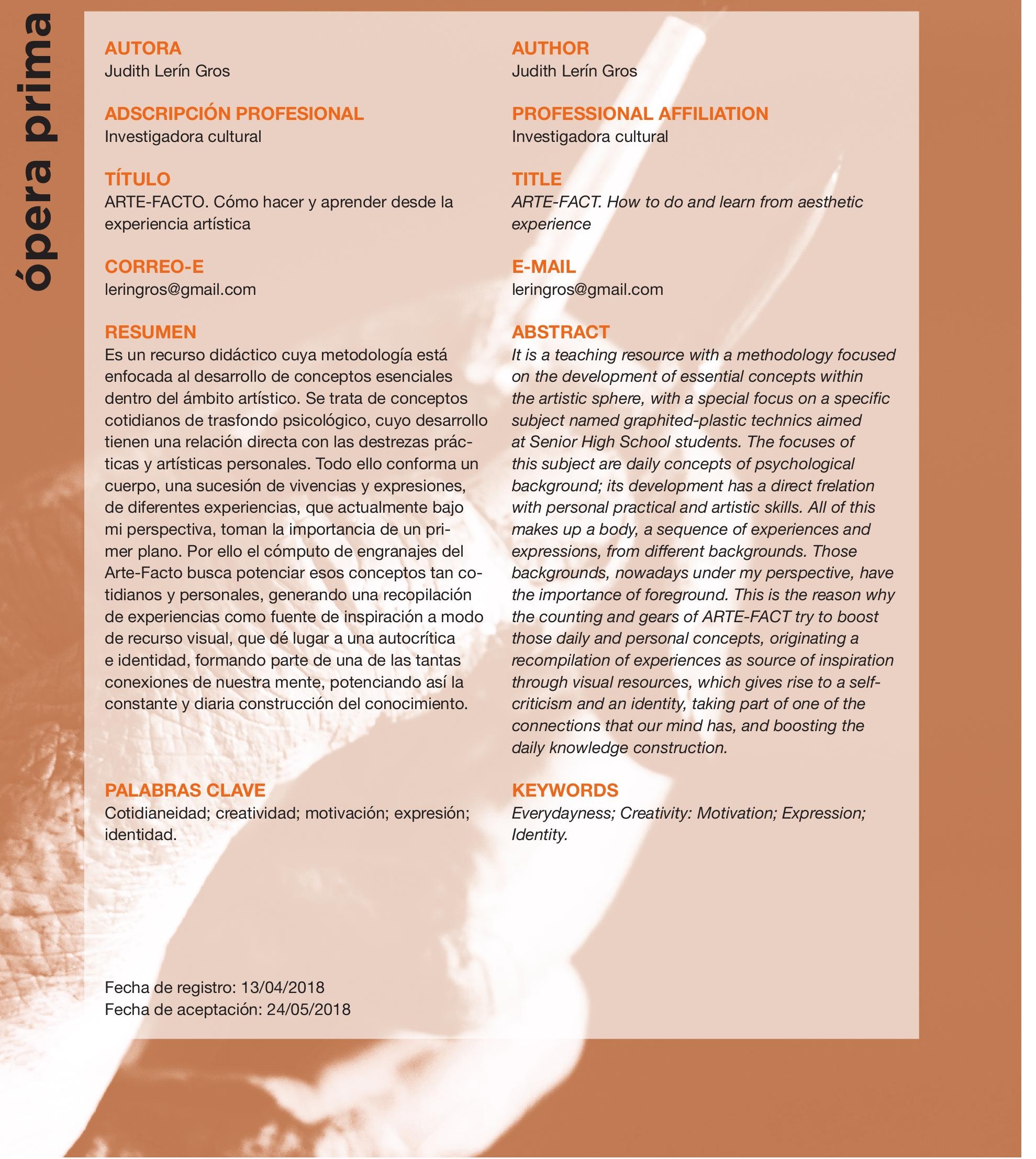




\section{ARTE-FACTO. Cómo hacer y aprender desde la experiencia artística Judith Lerín Gros}

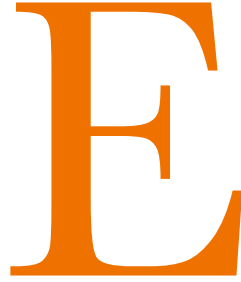

ste proyecto parte desde una provocación $\mathrm{o}$ intencionalidad, desde mi saber hacer y ser como persona, artista y consumidora de cultura, una reacción a las necesidades ausentes y cotidianas de nuestro entorno artístico-educativo.

Una respuesta, una propuesta a modo de acción, una innovación, un estímulo sobre creatividad, motivación, perspectiva, cotidianeidad e identidad-autocrítica, que tiene un impacto directo en la Educación, un Arte-Facto.

En relación a esta introducción y como inicio, quiero mencionar el IX Seminario del Observatorio Cultural del Proyecto Atalaya que tuvo lugar en la Universidad de Málaga los días 5 y 6 de Octubre de 2017, en concreto, la conferencia «El impacto educativo de la cultura» impartida por Alfons Martinell, Profesor emérito y Director honorífico de la Cátedra Unesco Políticas Culturales y Cooperación de la Universidad de Girona. Alfons Martinell explica, desde su experiencia, cómo se observan o desarrollan Cultura, Educación y Arte en la sociedad, aportando y proponiendo hitos o guías esenciales como hechos o propuestas todavía por resolver en nuestra actualidad.
Sobre el Impacto de la Cultura en la Educación. ¿Qué aporta? ¿Cómo? ¿Por qué?

A esta cuestión, desde mi perspectiva, se pone de manifiesto que el concepto «Entorno», como medio común, ya sea entorno social, entorno educativo, interno o externo. Con pequeñas acciones podemos promover la importancia de dicho concepto, que desde mi función como docente, su pretensión reside como raíz dentro del «Aula-espacio compartido», educando en valores y perspectivas. Lo cual podría tener o generar un impacto a lo largo del tiempo en cuanto a la Educación de esta generación, siendo conscientes y promoviendo un entorno sano, lleno de posibilidades, dónde confluyan y se relacionen de una forma cercana y directa Arte, Educación y Cultura (ya que funcionan por sistemas y estructuras diferentes), pudiendo dar así una respuesta contundente a las preguntas planteadas al inicio.

La práctica artística como Integración social. Cómo la práctica artística es una herramienta de las personas para encontrar un sentido de vida o formar parte de la sociedad.

Aquí se pone en cuestión algo fundamental, que todavía está en proceso y lucha. Con ello me refiero al reconocimiento de las Artes, como dice Alfons Martinell y yo apoyo

http://dx.doi.org/10.25267/Periferica.2018.i19.26 
directamente: «la formación artística a nivel de reconocimiento, está muy mal tratada en España». Desgraciadamente, esta cuestión es algo a mejorar, por la importancia que suponen las artes tanto en la educación como en los modos de vida e inteligencias múltiples.

La experiencia artística en referencia al valor que tiene el arte y sus aplicaciones, tanto a nivel individual como colectivo, es una iniciativa continua que debemos cultivar y desarrollar por su gran importancia y aplicación en diferentes ámbitos. En cuanto a los valores artísticos, me refiero al desarrollo de aptitudes y actitudes a nivel personal.

Hablando desde la educación artística como una de las principales áreas para su desarrollo, en concreto desde mi experiencia personal «aplicando la experiencia artística a la educación» podemos fomentar y potenciar las carencias que se ven implícitas tanto en los procesos artísticos como en otras áreas, con ello hago referencia a capacidades como cotidianeidad, creatividad, motivación, percepción, identidad o autocrítica entre otras. El desempeño de estas capacidades puede afianzar otros aspectos a nivel psicológico como autoestima, confianza, bienestar, expresividad, lo que conlleva una mejora en las relaciones intra e interpersonales. Por ello la respuesta a la cuestión: ¿Para qué sirven las Artes en la Educación? Entre las aptitudes innumerables que potencia y a parte del desarrollo de destrezas técnicas o expresivas, es capaz de incidir sobre: inteligencia emocional, autocrítica, aprender a pensar, capacidades esenciales que van a ser fundamentales en nuestro día a día, con nosotros y nuestro entorno.

Hablando en relación a la ciencia, psicología, o tecnología, las artes influyen en procesos de investigación 
y complementación de estas áreas. Pudiéndonos referir a manifestaciones a lo largo de la historia que representan los modos de vida - «el habitar» histórico--, la respuesta o reacciones directas ante conflictos, la búsqueda de nuevas formas de comunicación, del entendimiento interno de las personas como sujetos de análisis, el desarrollo y construcción de planteamientos innovadores, el acercamiento a la comprensión del lado derecho del cerebro, en definitiva, la concepción de una amplitud de información, donde solo las artes son capaces de interactuar con tal cantidad de materias vitales. Por ello, desde un nivel «singular» a un nivel «plural», las artes son fundamentales en nuestra cotidianeidad, en nuestras vidas.

esto?

¿Cómo o de qué forma podemos desarrollar todo

Se puede deducir en los párrafos anteriores que tal experiencia artística por su diversidad de desarrollos es una parte esencial dentro de la educación, pero ¿qué tipo de educación? Actualmente, si no es dentro de estudios específicos o especialidades artísticas, esta experiencia se ve reducida en cuanto a importancia a otras áreas o a intereses de cada persona, si los hay. De este modo, estaríamos hablando de una educación «individualizada de área». Si potenciamos esta definición haciéndola equivalente a la importancia de la experiencia artística, en la actualidad dentro y fuera de estudios especializados o dentro del panorama artístico contemporáneo, estaríamos hablando de una educación inter- y multi- disciplinar.

Somos artesanos, artistas, pero no solo eso, somos creadores, investigadores, innovadores, productores y generadores de nuevas perspectivas. Abarcamos gran variedad de lenguajes expresando a través de ellos, ¿Por qué no potenciar y adquirir el valor que nos pertenece? Desde mi experiencia, es necesario considerar las artes al mismo nivel que otras áreas y dentro de las propias artes promover esa interdisciplinariedad, que está en proceso y es una acción potente. De este modo, nos situamos en una adquisición de conocimientos por conexiones, lo que nos permite ir construyendo una red de información infinita, aumentando nuestra inteligencia, la estimulación de un cerebro emocional o un cerebro motivado, en relación a procesos psicológicos reales.

Tras reflexionar sobre la aportación que supone el proyecto, con un breve inciso en la importancia de la Cultura y resaltar la importancia de las Artes, voy a explicar los avances y temas más relevantes dentro de este trabajo, que como argumenté anteriormente y vuelvo a aclarar, se basan en mi experiencia personal aplicando la experiencia artística a la educación.

Esta propuesta de innovación nace bajo inquietudes e intereses propios, sobre la preocupación por un buen desarrollo personal de los alumnos, sobre su estado anímico en un medio compartido, entendido como espacio, que sería el aula, sobre su relación con el entorno, cuyos detonantes son carencias que pude presenciar durante mi experiencia temporal como docente en estudios de Bachiller de Artes. Por ello estos detonantes o carencias son el motivo principal que da lugar al planteamiento previo del proyecto de innovación, en concreto: Cotidianeidad. Creatividad. Motivación. Expresión. Identidad, cómo cité al inicio del texto.

Una vez determinados estos conceptos carentes en el aula, el siguiente planteamiento fue crear una estructura de investigación como metodología propia, para analizarlos desde una aproximación a su raíz científica y, posteriormente, relacionarlos con su desarrollo teórico-práctico artístico, potenciándolos, generando a partir de este análisis de investigación una segunda metodología aplicada a la práctica dentro y fuera del entorno del aula, un recurso visual que trata la idea de desarrollar los contenidos establecidos e ir más allá de crear sobre un papel en blanco, dando importancia tanto a la forma personal e impersonal, a modo de imágenes, como a la gran fuente de información y experiencias que supone.

En cuanto al eje de investigación se desarrolla dentro de la estructura como Metodología 1. Este eje está formado por tres secciones de piezas, que se complementan y dan lugar al siguiente punto.

SECGIÓN DE PIEZAS 1: Estudio Idea 1: Cotidianeidad / Creatividad / Motivación

Esta parte está conformada por hitos o guías, por artículos específicos sobre ciencia en referencia a la mente y al cerebro, por fuentes de información que van a la raíz de procesos psicológicos donde se generan las capacidades que conforman esta idea y por propuestas para llevarlas a cabo. Planteando temas y respondiendo a cuestiones como muestras de estudio:

1. Una mente no puede entenderse sin la cultura. (Lev Vygotsky)

Lev Vygotsky, psicólogo reconocido que trabaja en la rama del aprendizaje. Tanto la mente como el aprendizaje van ligados a la cultura y en conjunto forman una gran e importante influencia, que incide directamente en nuestro desarrollo. 
«La ciencia dice que la creatividad se puede entrenar y convertir en un hábito» ${ }^{1}$.

«Una habilidad es aquella que puedes aprender y aplicar en cualquier forma o tiempo, mientras un conocimiento implica solo comprender la causa y consecuencia de alguna situación» ${ }^{2}$ ¿Por qué la gente hace lo que hace?, ¿Cómo se expresa la motivación?, ¿Por qué es importante el cerebro?

Presentación de la obra de Joseph Kosuth, One and three chairs. 1965 en relación al Arte de lo Cotidiano.

SECGIÓN DE PIEZAS 2: Estudio Idea 2: Sensaciones / percepciones / pulsos innatos

Siguiendo con la línea como eje de investigación la idea que trata esta sección es: Ver cómo influyen sensaciones y percepciones como base del proceso de aprendizaje, para un conocimiento posterior.

Para ello, en primer lugar, se definen una serie de términos en relación, en concreto Percepción y Sensación, también se habla sobre un modelo de funcionamiento del cerebro El modelo de los borradores múltiples que explica el proceso de funcionamiento de las redes neuronales y por último se analiza un artículo de neuropsicología. Planteando temas y respondiendo a cuestiones como muestras de estudio:

«Las nociones de mente, cerebro y alma han ido evolucionando a lo largo de la historia gracias al trabajo de filósofos, sabios, médicos, escritores y revolucionarios» ${ }^{3}$.

«A diferencia de cualquier otra entidad empírica de la Naturaleza, la presencia de la mente le resulta inmediatamente obvia a sí misma, pero le es opaca a todos los observadores externos». ¿Cuántas veces nos hemos enfrentado a un papel en blanco?, ¿Cuántas veces hemos dudado antes de empezar a hacer cualquier trazo, de escritura, de dibujo, etc.?, ¿Por qué tener miedo a equivocarnos?

SEGGIÓN DE PIEZAS 3: Estudio Idea 3: Apropiación conceptual

Se trata de un glosario de palabras apropiadas, palabras con definiciones concretas que bajo mi percepción considero esenciales en el proceso educativo de enseñanza y aprendizaje.

Una vez realizado el análisis de los temas de investigación, el grueso del siguiente punto a desarrollar es Fracciones. Se trata de cinco modelos concretos de actividades desarrolladas a partir de la interiorización de toda la línea de investigación, con los que se pretenden desarrollar las carencias, citadas al inicio del texto, sin que los alumnos sean conscientes de ello, sin estar condicionados en su realización y cuyos resultados archiven en un soporte de libre configuración, aunque el prototipo realizado tiene forma de Fanzine, por la comodidad del formato.

Las actividades son las siguientes:

Sujetos: pretende desarrollar Creatividad, a partir de la traducción de varios fragmentos de texto a imágenes. Fue realizada por alumnos de Bachiller de Arte dentro de la asignatura de Técnicas grafico plásticas y en otro contexto por dos alumnos de bachiller de Arte y de Artes escénicas.

Lo propio y lo ajeno: pretende desarrollar Motivación, a partir de compartir perspectivas con los compañeros/ as tanto escritas, como representadas con técnica libre, como sonoras, contrastando los resultados de forma colectiva. Fue realizada por dos alumnos de bachiller de Arte y de Artes escénicas.

Pieza Acuática: pretende desarrollar la Perspectiva, a partir de la búsqueda de un lugar natural con agua en el entorno externo al aula, para captar sensaciones, formas, olores o colores del agua a través de una representación plástica.

Artesanos: pretende desarrollar la Cotidianeidad, a partir del trabajo por mejorar el funcionamiento del entorno interno del aula y valorar el proceso de creación de materiales y las opciones de desarrollo en diferentes materias, con armonía y responsabilidad.

Ambas no fueron realizadas debido a tiempo y programación, ya que a diferencia de las demás en estos dos casos se hace referencia al entorno externo e interno del aula.

Identidades: pretende desarrollar Autocrítica, a partir de su conciencia al generar una nueva identidad por medio de imágenes, responder a preguntas sobre valores de esa nueva identidad y sobre ellos mismos, para crear una representación como imagen crítica de ellos mismos, planteándose quién son, cómo son y qué lugar ocupan. Fue realizada por dos alumnos de bachiller de Arte y de Artes escénicas.

La suma de estas actividades da lugar al Recurso Visual, como fuente de información e inspiración al que poder recurrir como una conexión más en la construcción de nuestro conocimiento. De esta forma, la Metodología 1 como estructura de investigación da lugar a la Metodología 2 como Recurso visual. 


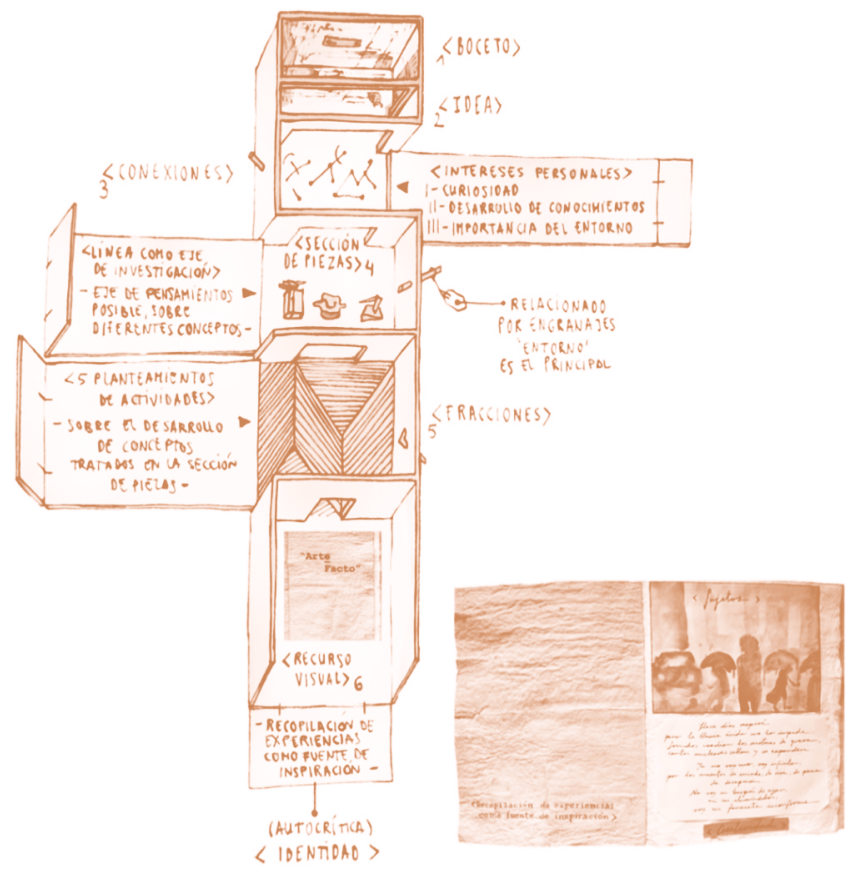

Imagen 1. Ilustración y fotografía sobre la representación de todo el proceso de investigación y un ejemplo de Recurso visual real

Hasta el momento, he llevado a cabo un desglose de la aplicación de estas metodologías y en concreto la Metodología 1 como estructura de investigación, con contenidos aplicados al desarrollo de la educación artística, pero, no obstante, esta estructura no solo respondería a las necesidades o apetencias de este ámbito en particular, sino que está pensada para ser aplicada en relación a otras áreas o materias, o incluso para que, dentro de esas áreas o materias generaran sus propios desarrollos de investigación siguiendo las pautas propuestas.
${ }^{*}$ ARTE

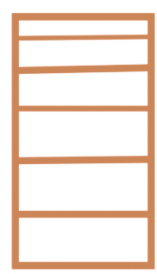

[ ${ }^{*}$ ARTE Y ${ }^{\wedge}$ CIENCIA]

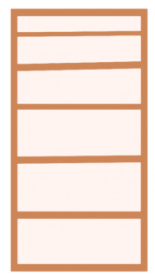

CIENCIA

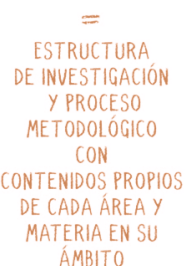

ÁMBITO
El objetivo de esta comunicación estructural es proponer y utilizar una herramienta, como elemento contenedor de información, que potencie la Multicisciplinariedad y la Interdisciplinariedad, entendiendo Multidisciplinariedad como el proceso a través del cual se buscan soluciones a un problema desde la aplicación de conocimientos de varias o múltiples disciplinas; e Interdisciplinariedad como el proceso a través del cual se da una cooperación entre varias disciplinas, con reciprocidad, provocando intercambios reales de conocimiento, con transferencia de métodos de una disciplina a otra.

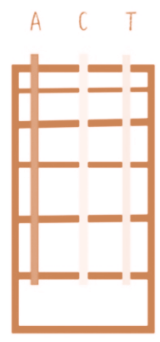

METODOLOGIA 1

ARTE, CIENCIA Y TECNOLOGÍA MISMO OBJETIVO Y ESTRUCTURA DIFERENTES CONTENIDOS

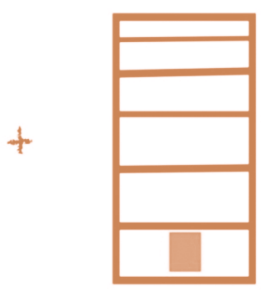

METODOLOGÍA ? RECURSO VISUAL EN EL CASO PRÁCTICO Y CONCRETO DESARROLLADO EN ARTE, MISMOS CONTENIDOS, VARIACIÓN DE FORMATO

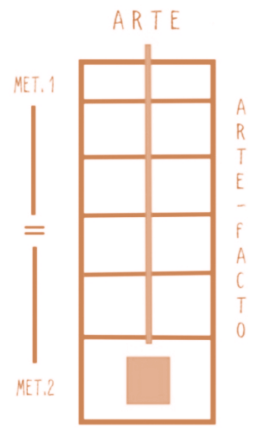

APLICABLE EN DIFERENTES MATERIAS, AREASY EDADES DE DESARROLLO
Imagen 3. Ilustración, ejemplo visual 3

Después de exponer los valores, por los que apuesta, los que conlleva, desarrolla y apoya todo este proceso y su funcionamiento, cómo último punto, voy a finalizar con la siguiente conclusión. Desde su raíz y mi práctica en el desarrollo dentro del aula como espacio compartido, considero esencial que para incentivar a los alumnos es necesario crear recursos para promover su motivación, los primeros que debemos estar motivados somos los docentes o futuros docentes. Compartiendo con los alumnos/as nuestras inquietudes, siempre que tengan un desarrollo enfocado a los objetivos que se nos planteen y a la calidad de las experiencias dentro del proceso de enseñanza-aprendizaje. La construcción del conocimiento comprende fases, desde las más simples en la infancia a las más complejas en la madurez, pero todo ello son fragmentos, fracciones, conexiones, ideas, bocetos y palabras sueltas que confluyen y dan lugar a pensamientos cada vez más amplios, que nos aportan una visión y aprendizaje personales. Por ello y atendiendo

Imagen 2. Ilustración, ejemplo visual 2 
a nuestra sencillez tenemos que ser conscientes de nuestra implicación diaria, de nuestra cotidianeidad, promoviendo nuestro desarrollo personal y construcción del conocimiento, dando importancia a nuestra inteligencia emocional y libre moral. En consecuencia, todo lo que merece la pena enseñar, desde una buena actitud y con posibilidad de formas o maneras aplicables, provoca que docentes y alumnos utilicemos y pongamos en práctica nuestras inteligencias múltiples.

A veces tan solo hace falta mirar a nuestro alrededor, prestar atención a lo que nos rodea, infinidad de engranajes invisibles que podemos observar, oler, escuchar, tocar y sentir, acciones básicas en nuestro comportamiento. El Arte-Facto como proyecto de innovación, recurso didáctico y generador de un recurso metodológico y visual, comprende infinidad de imágenes, cargadas de acciones básicas, de estimulaciones tanto internas como externas que conectan con nuestros pensamientos, desarrollando inquietudes, percepciones sobre el entorno que nos rodea y lo más importante, constituye una conexión más en la construcción de nuestro conocimiento.

\section{Notas}

(1) GARZO, I. (2015). «Trucos demostrados contra los bloques creativos». Yorokobu (fecha de consulta: 15/07/2016) http://www.yorokobu.es/trucos-demostrados-creatividad/

(2) (2016). «Cómo aprender más rápido y mejor». Doméstica (fecha de consulta: 19/07/2016) http://www.domestika.org/es/blog/152-como-aprender-mas-rapido-y-mejor

(3) KOCH, G. (2016). «Una sucinta historia del alma». MENTE \& CEREBRO, n ${ }^{\circ} 78$, p. 88.

Aceptado: 29/09/2018 